Web Watch follows issues relevant to tobacco control on the world wide web. The emphasis is on new sites $\vec{\circ}$ or new features appearing on the web, including relevant URLs and short descriptions of the material. $A-$ web site is available featuring the URL links referenced in this column and in past columns; the URL is: $\vec{\omega}$ $<$ http://www.gate.net/ jcannon/webwatch/>.

\section{Children and tobacco}

TIPS FOR KIDS

<http://www.cdc.gov/nccdphp/osh/tipskids.htm> TIPS FOR TEENAGERS

$<h t t p: / / w w w . c d c . g o v / n c c d p h p / o s h / t i p s t e e n . h t m>$

The Office on Smoking and Health (OSH), National Center for Chronic Disease Prevention and Health Promotion, US Centers for Disease Control and Prevention (CDC), has prepared these two sites to acquaint children with the dangers of tobacco products and to promote tips on resisting peer pressure.

Both sites feature the $S G R 4 K i d s$ magazine. Written by the US Surgeon General to teach kids everywhere about the dangers of tobacco, the magazine features all kinds of interesting facts and information. The opinions of kids across the country and the opinions of their friends about smoking are expressed in their own words and ideas. Topics range from basic facts concerning children and tobacco to a discussion of smokeless tobacco, plus projects to "Make your world smoke-free!"

The "I QUIT!" booklet offers cessation information for teenagers who want to find out how to quit smoking.

Teenage opinions on smoking are presented from a nationwide poll. The poll results show that smoking is about the least popular thing you can do if you want to hang out with other teenagers-important information for teenagers feeling peer pressure to start using tobacco. A gallery of posters is displayed with messages proving that smoking is not what some people say it is. Take the online quiz and receive a free poster in the mail.

And finally, "What's really in?" (that cigarette). Answer: formaldehyde (a preservative for dead frogs), cyanide (rat poison) and, of course, nicotine (an addictive, potent insecticide found in insect spray).

FDA'S CHILDREN AND TOBACCO

$<$ http://www.fda.gov/opacom/campaigns/ tobacco.html>

Web Watch is prepared by fack Cannon. Send correspondence to him by email:

jcannon@gate.net
(FDA's) Children and Tobacco web site offers a wealth of information about the FDA regulations, the devastating health effects of tobacco on our nation's children and adolescents, and what retailers and consumers can do to help reduce tobacco use by young people.

LIFESTYLE SMOKEFREE

$<$ http://www.wce.ac.nz/sun/smokefree.html>

$<$ http://www.wce.ac.nz/sun/smokefree/junior/ smoke.html>

$<$ http://www.wce.ac.nz/cancer/

lifestyles_smokefree/smokefreecont.html>

From New Zealand, these developing sites have been initiated within the partnership of the Wellington College of Education, New Zealand, and the Wellington Division of the Cancer Society of New Zealand. Modules are offered for children of all ages.

Here is Maddie's response: "I don't like smoke because it makes me wheeze and I can't go and play with my friends."

For the very young, a quiz features cartoonlike caricatures of various items to which a "Yucky" or "Yummy" response can be made. A cigarette is the yuckiest item on the menu.

Animated GIFs (graphics files) are used to represent what smoke can do to the body.

Menu selections are available for adults and mature adolescents. Subjects range from "Smoking facts of Maori" to "Parenting smokefree children".

NICNET: KIDS AND SMOKING ISSUES

$<h t t p: / / w w w . m e d l i b$. arizona.edu/ pubhlth/ kids.htm>

The Arizona Nicotine and Tobacco Network of has developed a nice web site featuring information relevant to children and tobacco. In addition to some hard-hitting images, a selection of links and online material is divided between "Elementary school and junior high school ages" and "High school age 14-18 yrs".

\section{CDC's TIPS: Tobacco Information and Prevention Sourcepage \\ $<h t t p: / / w w w . c d c$. gov/tobacco/>}

$\mathrm{OSH}$ has also expanded its database on smoking, tobacco, and health. Most of the information is available in published documents, and can be obtained by leaving a voice recording, by sending a fax, or through the $\mathrm{OSH}$ internet home page.

The OSH web site features news with links to articles in CDC's Morbidity and Mortality 


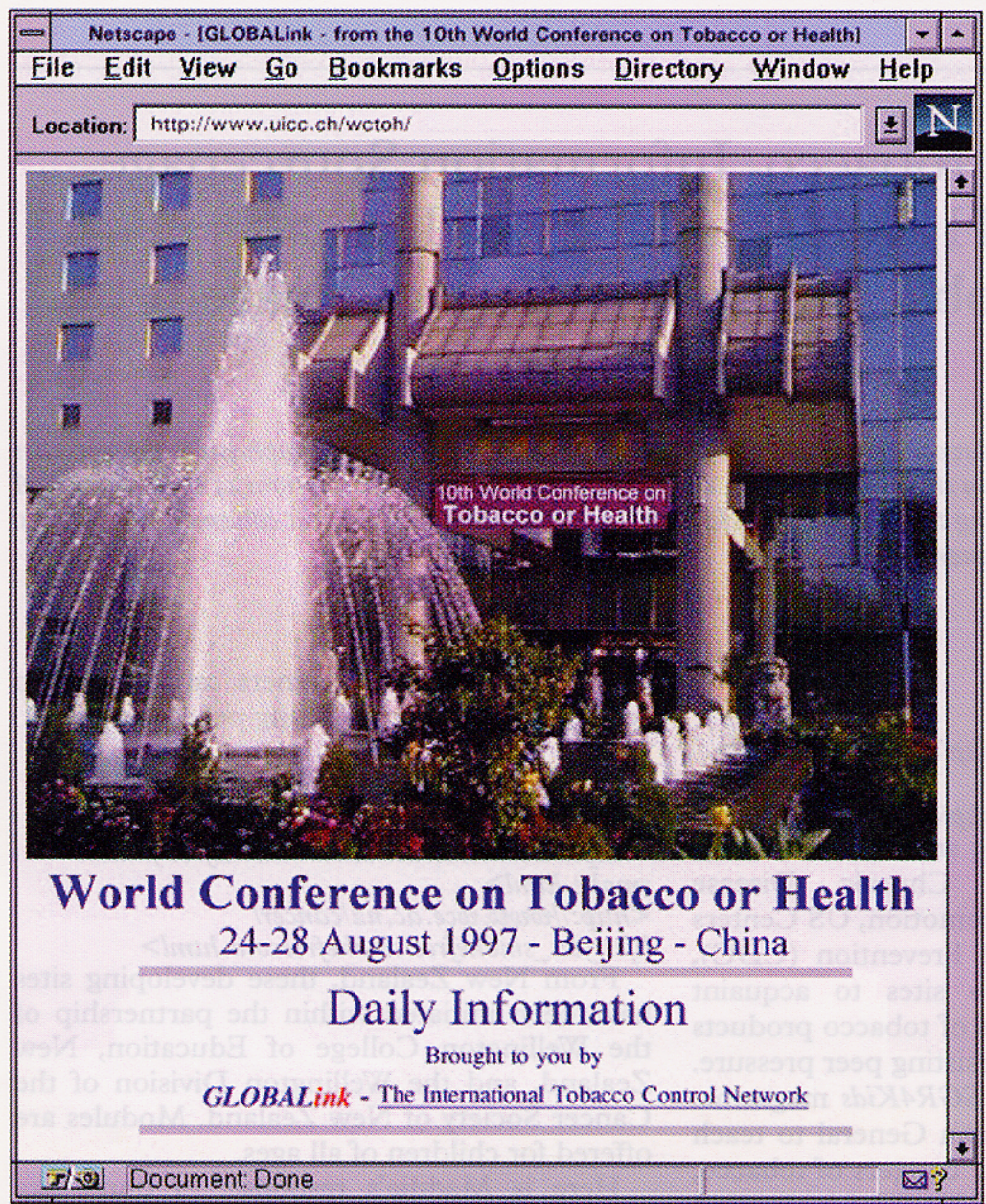

Web site for the 10th World Conference on Tobacco or Health.

Weekly Report; information on the Surgeon General's reports; cessation information and guidelines; new citations of recently published, tobacco-related articles from the behavioural, scientific, and technical literature; plus educational materials featuring a wide variety of selections for everyone including employers, health professionals, parents, educators, and youth group leaders.

The database covers more than 30 years of information and contains more than 60000 abstracts of the scientific and technical literature related to smoking and tobacco use.

\section{CDC WONDER on the web}

$<h t t p: / / w o n d e r . c d c . g o v />$

A CDC data service called WONDER is available for searching the CDC database through the internet. Single-point access to a variety of CDC reports and guidelines is provided.

Also available through wONDER as a PC/DOS application is Tables and Graphs. This downloadable program allows an epidemiologist to manipulate numerical data extracted from WONDER numerical data sets. Working in a spreadsheet environment, one can produce presentation-quality graphics in bar graphs, pie charts, or even geographical representations of the data from WONDER.

\section{0th World Conference on Tobacco or} Health

<http://www.globalink.org/wctoh/report/> $<$ http://www. uicc.ch/wctoh/>

Miss your flight to Beijing on 24-28 August? Go to either of these two sites for each day's agenda, press releases, and even photos taken by Ruben Israel (figure). Also available are the resolutions, keynote address, proceedings, and next conference information-plus Neil Collishaw's An international framework convention for tobacco control.

\section{World Health Organisation}

GLOBAL STATUS REPORT

<http://www.cdc.gov/nccdphp/osh/who/

whofirst.htm>

For tobacco-related information specific to individual countries, the World Health Organisation offers this site.

Subjects include: sociodemographic characteristics, age-standardised annual death rate per 100000 , tobacco production, trade and industry, tobacco consumption, smoking prevalence, mortality from tobacco use, and a description of the country's tobacco control measures.

\section{TOBACCO OR HEALTH PROGRAMMES}

<http://www.who.org/programmes/psa/toh.htm>

The World Health Organisation (WHO) also offers these tobacco-related publications: Tobacco Alert, a quarterly bulletin; The tobacco epidemic: a global public health emergency; WHO press releases and fact sheets; selected list of WHO publications on tobacco or health; and the full text of selected WHO documents on tobacco or health.

\section{Tobacco Control Super Site}

$<$ <ttp://www.health.su.oz.au/tobacco/>

From Australia, this site has been constructed by Professor Simon Chapman, associate professor of public health in the Department of Public Health and Community Medicine, University of Sydney; deputy editor of Tobacco Control, and member of the WHO Expert Advisory Panel on Tobacco and Health.

Selection of links was made on those most useful for public health researchers and advocates in addressing contemporary issues in international tobacco control, and others which give particular emphasis to Australia.

Don't miss Chapman's Diary of Denial, <http://www. health.su.oz.au/tobacco diaryofd.htm>

In this compendium Professor Chapman details an Australian history of tobacco industry denials about the health effects of smoking, addictiveness of nicotine, and marketing of tobacco products to children.

\section{IRRC's Tobacco Information Service home page}

<http://www.irrc.org/profile/tis/tishome.htm>

The Investor Responsibility Research Center (IRRC) publishes the bi-monthly Investor's Tobacco Reporter newsletter under a 
grant from the Robert Wood Johnson Foundation. Its purpose is to keep institutional investors and others abreast of the rapidly changing environment for the tobacco industry and for tobacco investments.

Hardcopy and email subscriptions are available free of charge. Or if you prefer, each issue is available in its entirety on the web site.

Svein Martin's home page

<http://home.sol.no/ smp1000/>

More than 26000 cigarette packs from many countries around the world are available on the home page of this consultant to the Norwegian tobacco industry. Of particular ${ }^{-1}$ interest is the "Teddy" brand (as in "Teddy" Bear).

Theodore Roosevelt's trust-busting activities made him some kind of a hero to the Norwegian tobacco industry. So much so that in 1914, JL Tiedemann's Tobaksfabrik "honored" Roosevelt by launching a cigarette 응 brand named after him. The brand is still in $\frac{\bar{\phi}}{\bar{\phi}}$ production. (See Davis RM. "Teddy" Q cigarettes. Tobacco Control 1993;2:194.)

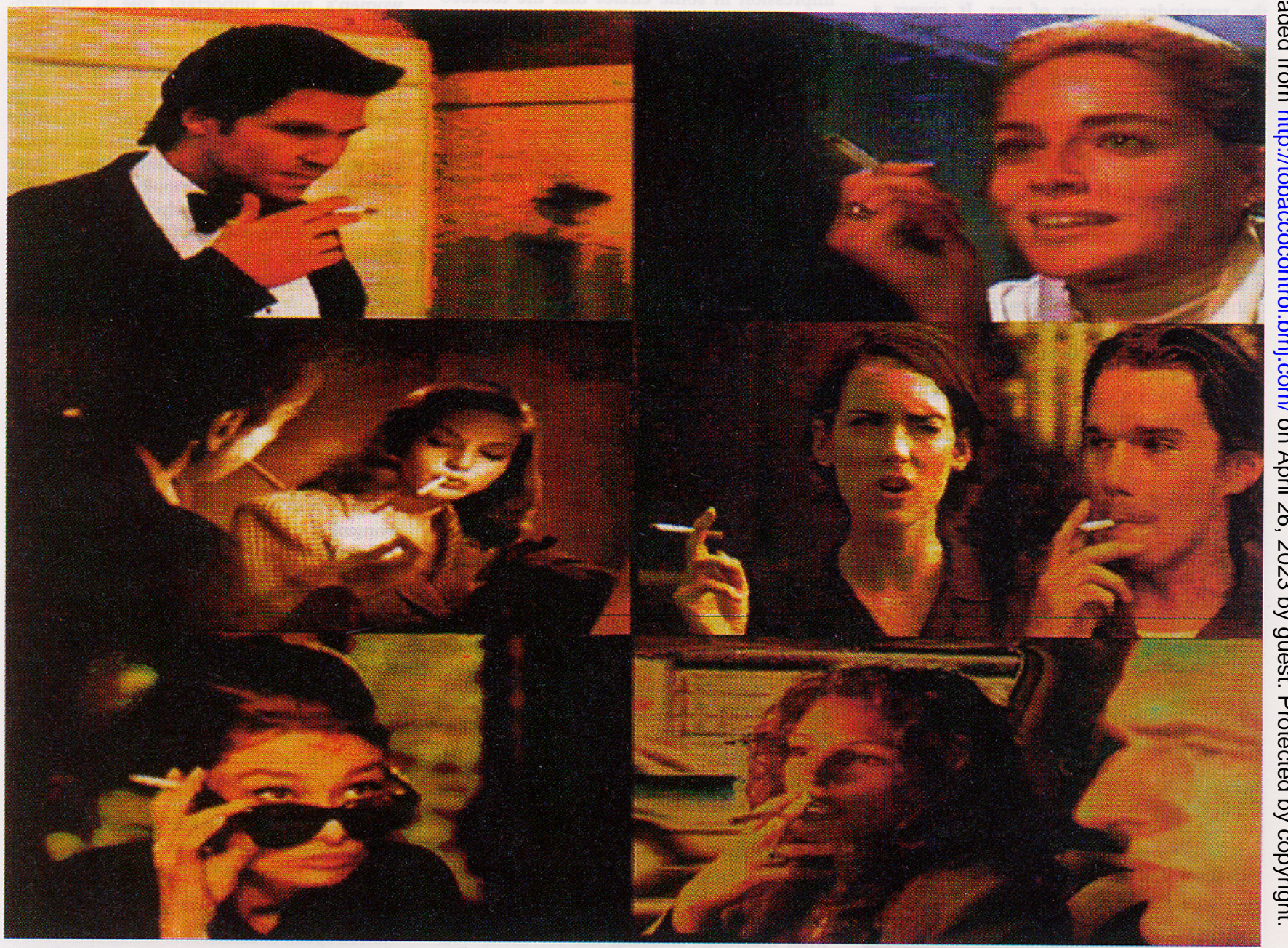

Smokes in the movies. A sampling of smoking scenes on celluloid, from the magazine Entertainment Weekly in an article on "Great exhalations" in its 16 fanuary 1998 issue. Clockwise from top left: Feff Bridges in The Fabulous Baker Boys; Sharon Stone in Basic Instinct; Winona Ryder and Ethan Hawke in Reality Bites; Fulia Roberts (with Rupert Everett) in My Best Friend's Wedding; Audrey Hepburn in Breakfast at Tiffany's; and Humphrey Bogart and Lauren Bacall in To Have and Have Not. 